\title{
ASPECTOS PSICOSSOCIAIS E ESTIGMATIZANTES DA LEISHMANIOSE CUTÂNEO-MUCOSA
}

\author{
Jackson Mauricio L. Costa', Kyola C. Vale'1, Iracema N. Cecilio², \\ Noberto K. Osaki', Eduardo M. Netto', Mauro S. Tada1, Flávio França1, \\ Maria do Carmo Barreto ${ }^{1}$ e Philip D. Marsden1
}

Os autores selecionaram 15 pacientes portadores de leishmaniose cutâneomucosa (LCM) forma grave, onde buscaram, através de entrevista psicológica, conhecer aspectos da vida de cada um, antes de contrair a doença, no decorrer e após o tratamento. Concomitantemente, realizaram 25 entrevistas com a comunidade onde residem os pacientes, com a intençâo de avaliar as reações da mesma ao doente com leishmaniose. Constataram que entre os pacientes entrevistados: $14(93,3 \%)$ referiram algum tipo de modificação no decorrer da doença; $11(73,3 \%)$ perceberam-se marginalizados; $9(60 \%)$ sentiram-se afastados do convivio da sociedade; $10(66,6 \%)$ tiveram dificuldade de retornar ao trabalho. Na comunidade, 11(44\%) associam o portador da LCM a individuos que apresentam deformações no corpo, 8(32\%) têm receio de contrair a doença pelo caráter destrutivo das lesões, 24(96\%) referiram que os pacientes têm problemas de relacionamento social.

Palavras chaves: Leishmaniose cutâneo-mucosa. Aspectos psicossociais. Estigmatização.

Segundo Schilder ${ }^{10}$, a imagem corporal nada mais é do que o modo pelo qual o corpo se apresenta para nós. Qualquer coisa que se origina no corpo ou que dele emana continua sempre a fazer parte desta imagem.

$O$ interesse do indivíduo pelo seu corpo e a importância social conferida ao mesmo ocorrem paralelamente ${ }^{10}$. Tanto que em determinadas doenças como a hanseníase ${ }^{2}$, a síndrome da imunodeficiência adquirida (SIDA) ${ }^{5}$, por demais conhecidas da classe médica, não só pelas complicações clínicas, mas também pelos fenômenos psicossociais e estigmatizantes que as mesmas produzem no decorrer de sua evolução, levam, não só os pacientes, mas também a sociedade de um modo geral a envolvimentos emocionais; tendo em vista que as emoções são sempre sociais, do mesmo modo que o pensamento também é uma função social, mesmo quando o individuo se encontra sozinho 310 .

Por outro lado, a leishmaniose cutâneo-mucosa, um dos grandes problemas de Saúde Pública do Brasil e de alguns países da América Latina, às vezes é confundida com a hanseníase, trazendo complicações emocionais aos pacientes ${ }^{3}$.

Trabalho realizado com auxílio financeiro da USPTs GRANT AI 16282-04.

1. Núcleo de Medicina Tropical e Nutrição. Universidade de Brasília, 70910 Brasilia, DF.

2. Estudante de Graduação em Psicologia da Universidade de São Paulo (USP)

Recebido para publicação em 5/5/86.
Torres $^{12}$ na Bahia e Tejada ${ }^{11}$ no Peru, citam casos de envolvimento psíquico marcante nos indivíduos que desenvolveram as formas graves da leishmaniose cutâneo-mucosa em suas casuísticas.

No decorrer de dez anos de trabalho em área endêmica de leishmaniose tegumentar americana no interior da Bahia (Três Braços e Corte de Pedra), pôde-se observar os transtornos psicológicos e sociais vividos pelos pacientes. Isto motivou-nos a estudar os aspectos psicossociais da leishmaniose cutâneo-mucosa através de entrevistas psicológicas com os pacientes e com a comunidade em que vivem, buscando também constatar o fenômeno da estigmatização.

\section{MATERIAL E MÉTODOS}

Através da confiança e amizade dos pacientes, assim como da comunidade, foi possível entrevistá-los buscando colher o maior número possivel de informaçōes da vida dessas pessoas, seus relacionamentos sociais e individuais, suas atividades profissionais e de recreação, o significado da doença leishmaniose em suas vidas, sua postura de paciente ou de membro da comunidade convivendo com pacientes, informações sobre a leishmaniose, dentre outros aspectos.

Foram entrevistados 15 pacientes selecionados entre aqueles que apresentavam maiores transtornos psicológicos e sociais em decorrência da doença, incluindo-se portadores da forma cutânea e mucosa. Dos 15 entrevistados, dois ainda estavam em tratamento (Tabela 1). 
Costa JMR, Vale KC, Cecilio IN, Osaki NK, Netto EM, Tada MS, França F, Barreto MC, Marsden PD. Aspectos psicossociais e estigmatizantes da leishmaniose cutaneo-mucosa. Revista da Sociedade Brasileira de Medicina Tropical 20 : 77-82, Abr-Jun, 1987.

Tabela 1 -Pacientes envolvidos no estudo.

\begin{tabular}{lclll}
\hline LTB/LTCP*** & $\begin{array}{c}\text { Idade/Sexo/ } \\
\text { Condiçâo Clínica }\end{array}$ & Procedência & Estado Civil & Grau de Instrução/Profissäo \\
\hline 0014 & 69/M Cut/Muc. & Itamari & Casado & Analfabeto/Lavrador \\
0364 & 36/M Muc. & Três Braços & Solteiro & Analfabeto/Lavrador \\
$0504^{*}$ & 40/M Muc. & Corte de Pedra & Casado & Analfabeto/Lavrador \\
0649 & 40/F Cut. & Teolândia & Solteira & Analfabeta/Doméstica \\
0010 & 18/F Cut/Muc. & Três Braços & Solteira & Analfabeta/Doméstica \\
0306 & 20/F Cut. & Três Braços & Solteira & Analfabeta/Lavradora \\
0011 & 61/F Muc. & Três Braços & Solteira & Primário/Doméstica \\
0012 & 28/M Muc. & Cravolândia & Solteiro & Primário/Comerciante \\
0475 & 23/M Muc. & Tabuleiro & Solteiro & Analfabeto/Lavrador \\
0387 & 32/M Muc. & Poções & Casado & Analfabeto/Lavrador \\
0378 & 32/M Muc. & Itamari & Solteiro & Analfabeto/Lavrador \\
0488 & 37/M Muc. & Corte de Pedra & Casado & Primário/Motorista \\
0259 & 54/M Muc. & Jiquiriçá & Casado & Analfabeto/Lavrador \\
0027 & 19/M Muc. & Três Braços & Solteiro & Analfabeto/Lavrador \\
$0725^{*}$ & 16/F Cut. & Corte de Pedra & Solteira & Primário/Lavradora \\
& & & &
\end{tabular}

\footnotetext{
* Pacientes ainda sob tratamento

* LTB (Leishmaniose Três Braços)

LTCP (Leishmaniose Tegumentar Corte de Pedra)
}

A entrevista elaborada por um dos autores (JMLC), compreendia três partes, as quais questionavam aspectos da vida do paciente, antes, no decorrer da doença e após tratamento. As mesmas foram realizadas por 3 membros da equipe: um médico, uma estudante de Psicologia e uma estudante do Curso de Medicina, devidamente orientados. A entrevista continha questões subjetivas envolvendo, principalmente, o relacionamento do paciente com sua familia, amigos, e com o sexo oposto em função da doença.

Em relação à comunidade, foi utilizado o mesmo instrumento para se obter as informações. A entrevista aplicada seguiu os mesmos parâmetros da utilizada por Gandra Júnior ${ }^{3}$, através de questões subjetivas, abordando a postura da comunidade em relação à doença e ao doente, procurando, também avaliar a imagem social do portador da leishmaniose $e$ seu grau de estigmatização. Aleatoriamente, foram incluidos um total de 25 indivíduos sadios da comunidade em que os pacientes residiam.

\section{RESULTADOS}

As entrevistas dos pacientes foram avaliadas através do grupamento de respostas semelhantes ou que continham a mesma idéia, com as quais tabulamos os dados. As principais respostas obtidas nas três fases da entrevista encontram-se na Tabela 2 . Em 3 dos 15 pacientes (LT B 10, 14 e 364) a doença marcou suas vidas.

A paciente LTB 10 era uma jovem de 18 anos, cuja familia com 14 componentes foi acometida pela leishmaniose. A mesma é marcada em sua comunidade, juntamente com suas dez irmãs. Apenas uma se casou, com rapaz de outra localidade.

O paciente LTB 14, quando contraiu a doença, afastou-se por iniciativa própria de sua familia, construiu uma casa nos fundos da pequena fazenda de seu irmão, saindo apenas à noite; desta maneira sobreviveu por vários anos, abstendo-se de qualquer visita mesmo familiar. As Figuras 1 e 2, mostram aspectos de sua imagem corporal antes e após terapêutica.

O mesmo aconteceu com o LTB 364; adoeceu quando era muito jovem, após a cura clínica permaneceu grave seqüela da doença, que deformou sua face. Residia com um tio, também portador de lesão musosa grave, um dos primeiros casos isolados de Leishmania braziliensis braziliensis em Três Braços (PD, Marsden: informação pessoal). Este rapaz, hoje com 34 anos de idade, não consegue manter um bom convivio com o sexo oposto. A Figura 3 mostra o grau de destruição causado pela doença neste jovem.

$\mathrm{Na}$ comunidade, as pessoas entrevistadas foram distribuidas da seguinte maneira: 12 individuos (48\%) eram do sexo masculino e $13(52 \%)$ sexo feminino. Todos tinham idade igual ou superior a 20 anos, 21 indivíduos $(84 \%)$ eram casados, $10(40 \%)$ eram lavradores e $24(96 \%)$ tinham como religião o catolicismo.

Existiu entre os entrevistados a preocupação com a doença, seus aspectos profiláticos e métodos de reconstrução cirúrgica. Os mesmos vêem os porta- 
Costa JML, Vale KC, Cecilio IN, Osaki NK, Netto EM, Tada MS, Franca F, Barreto MC, Marsden PD. Aspectos psicossociais e estigmatizantes da leishmaniose cutâneo-mucosa. Revista da Sociedade Brasileira de Medicina Tropical 20: 77-82, Abr-Jun, 1987.

Tabela 2 - Resumo das principais respostas obtidas dos 15 pacientes entrevistados

\begin{tabular}{|c|c|c|c|c|c|c|c|c|c|c|c|}
\hline $\begin{array}{l}\text { 1. Aspectas do periodo anterior } \\
\text { a doença }\end{array}$ & Respostas & $\begin{array}{c}N, \mathrm{de} \\
\text { Respostas }\end{array}$ & $\%$ & $\begin{array}{l}\text { 2. Aspecros do decorrer da } \\
\text { doenfa }\end{array}$ & Respostas & $\begin{array}{c}\text { No de } \\
\text { Respostas }\end{array}$ & $\%$ & $\begin{array}{l}\text { 3. Aspectos do periodo após a } \\
\text { doença }\end{array}$ & Respostas & $\begin{array}{l}\text { Nos de } \\
\text { Respostas }\end{array}$ & $\%$ \\
\hline $\begin{array}{l}\text { 1.1. Qualidade de vida (aspec- } \\
\text { tos gerais, trabalhos, hábi- } \\
\text { tos etc.) }\end{array}$ & $\begin{array}{l}\text { Sem proble- } \\
\text { mas }\end{array}$ & 14 & 93 & $\begin{array}{l}\text { 2.1. Qualidade de vida (com- } \\
\text { prometimento do trabalho) }\end{array}$ & $\begin{array}{l}\text { Com proble- } \\
\text { mas }\end{array}$ & 12 & 80 & 3.1. Em relação ao trabalho & $\begin{array}{l}\text { Tiveram pro- } \\
\text { blemas de rein- } \\
\text { tegaģăo do } \\
\text { trabalho }\end{array}$ & 10 & 66 \\
\hline 1.2. Relacionamento familiar & Bom & 34 & 93 & $\begin{array}{l}\text { 2.2. Alteraçóes no relaciona- } \\
\text { mento social }\end{array}$ & $\begin{array}{l}\text { Afastamento } \\
\text { das pessoas om } \\
\text { releçâo ao pa- } \\
\text { ciente }\end{array}$ & 9 & 60 & 3.2. Em Relaçāo ao sexo oposto & $\begin{array}{l}\text { Tiveram difi- } \\
\text { culdade de re- } \\
\text { lacionamento }\end{array}$ & 9 & 60 \\
\hline $\begin{array}{l}\text { 1.3. Relacionamento com o se- } \\
\text { xo oposto }\end{array}$ & Bom & 34 & 93 & $\begin{array}{l}\text { 2.3. Opiniāo do paciente en re- } \\
\text { lação as modificaçōes de- } \\
\text { correntes da doença }\end{array}$ & $\begin{array}{l}\text { Referem mo- } \\
\text { dificaçōes }\end{array}$ & 14 & 93 & 3.3. Crença religiosa & $\begin{array}{l}\text { Crença Inal- } \\
\text { terada }\end{array}$ & 10 & 67 \\
\hline 1.4. Principal atividade & $\begin{array}{l}\text { Trabalho na } \\
\text { roça }\end{array}$ & 10 & 66 & $\begin{array}{l}\text { 2.4. Causas do afastamento do } \\
\text { paciente }\end{array}$ & $\begin{array}{l}\text { Vergonhs de } \\
\text { sua imagem }\end{array}$ & 5 & 33 & $\begin{array}{l}\text { 3.4. Expectativa dos pacientes } \\
\text { em relação a equipe de saú- } \\
\text { de que atua no local. }\end{array}$ & $\begin{array}{l}\text { Que solucio- } \\
\text { nem os pro- } \\
\text { blemas decor- } \\
\text { rentes da LCM }\end{array}$ & 15 & 100 \\
\hline 1.5. Participaçāo em atividades & $\begin{array}{l}\text { Jogos, festas, } \\
\text { bares }\end{array}$ & 12 & 80 & $\begin{array}{l}\text { 2.5. Sentimento de marginali- } \\
\text { zaçáo }\end{array}$ & $\begin{array}{l}\text { Sentiam-se } \\
\text { marginalizá- } \\
\text { dos }\end{array}$ & 11 & 73 & $\begin{array}{l}\text { 3.5. Medo de adoecer nova- } \\
\text { mente }\end{array}$ & Sim & 15 & 100 \\
\hline 1.6. Crençą religiosa & Católicos & 13 & 87 & $\begin{array}{l}\text { 2.6. Reaçāo da comunidade em } \\
\text { relação aos pacientes se- } \\
\text { gundo estes }\end{array}$ & $\begin{array}{l}\text { Demonstravam } \\
\text { nojo } \\
\text { Evitam se a- } \\
\text { proximar } \\
\text { Demonstram } \\
\text { medo de con- } \\
\text { trair a doen- } \\
\text { ça } \\
\text { Zombavam de } \\
\text { sua aparència }\end{array}$ & $\begin{array}{l}2 \\
4\end{array}$ & $\begin{array}{l}13 \\
27\end{array}$ & & & & \\
\hline
\end{tabular}

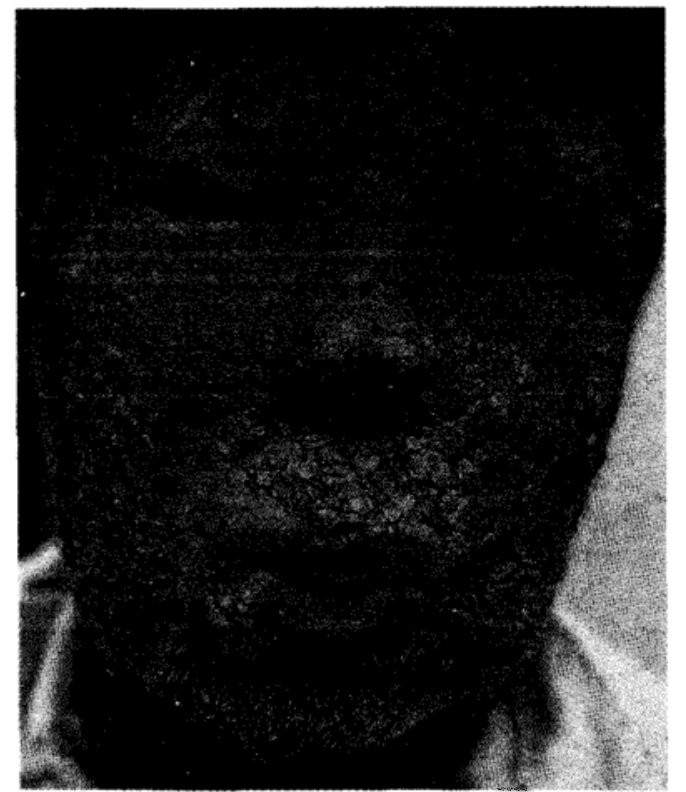

Fig. 1-LTB 014: aspectos deformantes durante a doença, perda do nariz cartilaginoso, erupção eczematóide produzida pela leishmaniose.

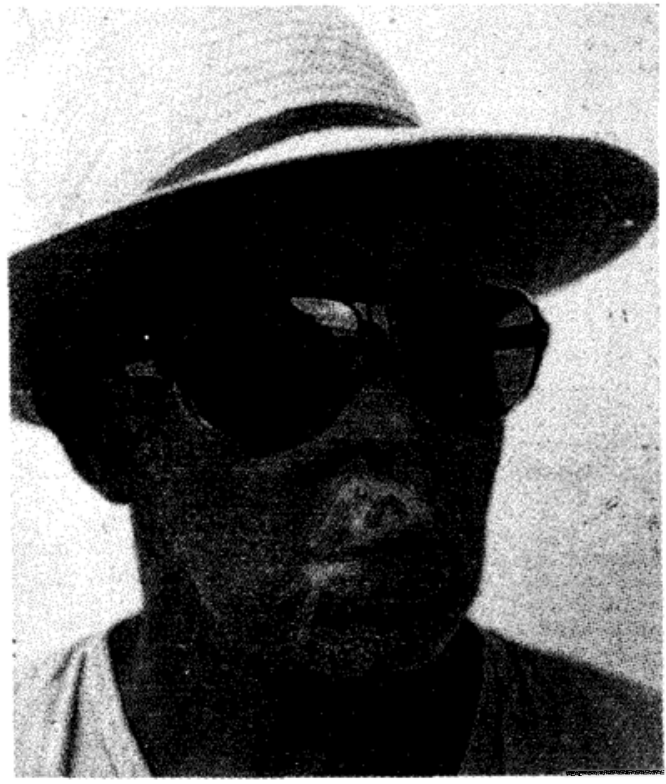

Fig. 2 - Aspecto do mesmo paciente após cura clínica mostrando como medida simples, óculos escuro, e chapéu, melhorou cosmeticamente o paciente. 


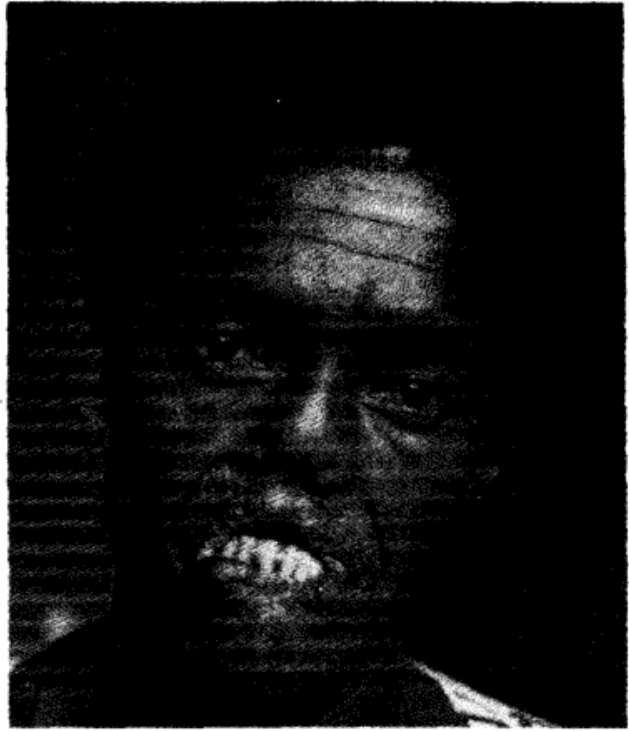

Fig. 3 - LTB 364: observa-se o grau de destruição, mesmo após a cura clínica da doença.

Tabela 3 - Resumo das principais respostas obtidas dos 25 membros da comunidade entrevistados.

\begin{tabular}{|c|c|c|c|}
\hline Perguntas & Respostas & No Casos & $\%$ \\
\hline $\begin{array}{l}\text { 1. Doença que mais teme con- } \\
\text { trair }\end{array}$ & Càncer & 18 & 72 \\
\hline $\begin{array}{l}\text { 2. Entre a doença que mais te- } \\
\text { me contrair, lepra e leish- } \\
\text { maniose, qual destas prefe- } \\
\text { ra ter. }\end{array}$ & $\begin{array}{l}\text { Leishmaniose } \\
\text { Lepra }\end{array}$ & $\begin{array}{l}16 \\
7\end{array}$ & 28 \\
\hline $\begin{array}{l}\text { 3. Imagem fisica do paciente } \\
\text { com LTA }\end{array}$ & $\begin{array}{l}\text { Com feridas no corpo } \\
\text { Corpo deformado }\end{array}$ & $\begin{array}{r}11 \\
9\end{array}$ & $\begin{array}{l}44 \\
36\end{array}$ \\
\hline $\begin{array}{l}\text { 4. Temor de contrair a leish- } \\
\text { maniose }\end{array}$ & $\begin{array}{l}\text { Pelo caráter destrutivo da lesão } \\
\text { Pela dificuldade de tratamento } \\
\text { Por pensar que é transmissivel }\end{array}$ & $\begin{array}{l}8 \\
7 \\
3\end{array}$ & $\begin{array}{l}32 \\
28 \\
12\end{array}$ \\
\hline $\begin{array}{l}\text { 5. Capacidade de identificaçāo } \\
\text { de um paciente com leish- } \\
\text { maniose }\end{array}$ & $\operatorname{Sim}$ & 18 & 72 \\
\hline $\begin{array}{l}\text { 6. Elementos de identificação } \\
\text { do paciente com leishma- } \\
\text { niose }\end{array}$ & Vendo a ferida & 14 & 56 \\
\hline 7. Informações sobre a doença & $\begin{array}{l}\text { Demora a curar } \\
\text { Produzida por mosquitos } \\
\text { Não é contagiosa }\end{array}$ & $\begin{array}{l}8 \\
4 \\
2\end{array}$ & $\begin{array}{r}32 \\
16 \\
8\end{array}$ \\
\hline $\begin{array}{l}\text { 8. Existência de estórias, len- } \\
\text { das ou anedotas envolvendo } \\
\text { a doença e o doente }\end{array}$ & Nāo & 24 & 96 \\
\hline $\begin{array}{l}\text { 9. Imagem psicológica do pa- } \\
\text { cienţe }\end{array}$ & $\begin{array}{l}\text { Sente vergonha do corpo } \\
\text { Tem problemas no relaciona- } \\
\text { mento }\end{array}$ & $\begin{array}{l}12 \\
12\end{array}$ & $\begin{array}{l}48 \\
48\end{array}$ \\
\hline $\begin{array}{l}\text { 10. Reaçāo caso recebesse } \\
\text { diagnóstico de leishmaniose }\end{array}$ & $\begin{array}{l}\text { Procurava tratamento } \\
\text { Ficaria deprimido }\end{array}$ & $\begin{array}{r}20 \\
4\end{array}$ & $\begin{array}{l}80 \\
16\end{array}$ \\
\hline $\begin{array}{l}\text { 11. Relato de convivência com } \\
\text { familiares de pacientes }\end{array}$ & $\begin{array}{l}\text { Sim } \\
\text { Não }\end{array}$ & $\begin{array}{l}13 \\
12\end{array}$ & $\begin{array}{l}52 \\
48\end{array}$ \\
\hline $\begin{array}{l}\text { 12. Relato de convivència com } \\
\text { pacięntes }\end{array}$ & $\begin{array}{l}\text { Sim } \\
\text { Não }\end{array}$ & $\begin{array}{r}21 \\
4\end{array}$ & $\begin{array}{c}84 \\
16\end{array}$ \\
\hline
\end{tabular}

dores de leishmaniose cutâneo-mucosa como individuos que apresentam deformidades e feridas no corpo. Os detalhes das principais respostas obtidas na entrevista encontram-se na Tabela 3.

\section{DISCUSSÃO}

Apesar de a leishmaniose ser endêmica na região estudada observou-se que a população, de um modo geral, não está informada sobre a etiologia e a prevenção da doença. Recentemente, Netto e cols ${ }^{7}$ observaram que a população de Três Braços (Bahia) tinha um razoável entendimento somente sobre alguns aspectos epidemiológicos e terapêuticos da mesma.

Sabemos que, utilizar uma entrevista psicológica visando obter dados intimos de indivíduos, é tarefa difícil, só se tornando possivel após adquirirmos a confiança da população estudada. A nossa permanência na regiāo por 10 anos, assistindo a comunidade nos mais diferentes problemas médicos e sociais, possibilitou a obtenção dos dados pessoais dos pacientes e da comunidade aqui reportados.

Neste estudo observamos como a doença traz problemas psíquicos e estigmatizantes, pois dos 15 pacientes entrevistados, $9(60 \%)$ referiram que as pessoas se afastavam deles, enquanto $11(73 \%)$ sentiram-se marginalizados em sua comunidade. Além do mais é uma doença debilitante para o trabalho pois $12(80 \%)$ dos pacientes tiveram dificuldades de exercer suas atividades, mesmo após a cura clínica; $10(66 \%)$ dos entrevistados ainda não retornaram ao trabalho.

Quando observamos o comportamento da comunidade foi notado que: 18 individuos $(72 \%)$ dos entrevistados, eram capazes de identificar um paciente com leishmaniose; $20(80 \%)$ acreditam que os pacientes apresentam deformidades e feridas no corpo; $12(48 \%)$ acham que os pacientes sentem vergonha de seu corpo; $20(80 \%)$ procurariam um médico, de imediato, para o seu tratamento caso fossem acometidos pela doença.

Notou-se, portanto, que tanto os pacientes como a comunidade sofrem com a doença tanto do ponto de vista clínico como do emocional: os doentes procurando tratamento médico, enquanto que a comunidade, em sua ignorância sob alguns aspectos da doença, evitando contato com os pacientes portadores, principalmente aqueles com as formas graves.

Nos casos em que desenvolvem seqüelas graves após a terapêutica, procede-se a reconstrução cirúrgica corretiva, como aconteceu com o LTB 14 o qual apresentava fibrose a nivel da pálpebra superior do olho direito, prejudicando a sua movimentação. $\mathrm{Pi}$ tanguy e Ribeiro ${ }^{8}$ relatam casos de reconstrução cirúrgica em portadores de seqüelas graves com bons resultados. Este procedimento sofre limitações quando do 
seu uso, pois os pacientes ao serem submetidos ao ato cirúrgico, devem apresentar reações sorológicas (IFI e/ou Elisa) negativos após a cura clínica. O que não se observa com frequêencia em área endêmica ${ }^{14}$.

O comportamento humano do problema é dificil de ser avaliado, pois a estigmatização é um dos fenômenos antigos da humanidade. Já nos tempos bíblicos os hansenianos eram amaldiçoados e obrigados ao confinamento até à morte, sendo que tais métodos foram mais agressivos no decorrer da Idade Média.

Nos tempos modernos instituiu-se o isolamento compulsório indiscriminado, onde os hansenianos eram obrigados a isolar-se para o resto da vida, de suas famílias e da comunidade em leprosários, verdadeiras cidades isoladas 29 .

O problema também é grave na doença de Chagas, onde a sociedade afasta de seu convivio o paciente chagásico; os serviços de saúde proíbem sua admissão ao trabalho, prática tão comum e discriminatória, simplesmente porque alguém apresenta um exame sorológico positivo para o Trypanosoma cruzi ${ }^{6}$.

Portanto, estamos diante de uma problema de cunho social grave que envolve diversos setores da sociedade: médicos, psicólogos, enfermeiros e a comunidade em geral. Há necessidade com urgência de medidas profiláticas que evitem doenças graves como a leishmaniose, hanseniase e doença de Chagas, cujas seqüelas fisicas, psicológicas e sociais tranformam sobremaneira a vida de seus portadores.

\section{$S U M M A R Y$}

The authors selected 15 patients with severe mucocutaneous leishmaniasis. By means of an interview concentrating on sociopsychological aspects they sought to understand aspects of the life of each patient before, during and after treatment of the disease. At the same time similar interviews were recorded on 25 healthy members of the same community to gauge their reaction to subjects with leishmaniasis.

Among the patients interviewed, in 14(93.3\%) their lives were affected by the disease and (73.3\%) were suffering from discrimination. Nine (60\%) felt di- vorced from society and $10(66.6 \%)$ had difficulty in returning to work. Of the healthy community members interviewed 11(44\%) associated the disease with bodily deformities and $8(32 \%)$ were afraid of catching the disease due its destructive nature. Twenty-four( $96 \%$ ) thought patients had social problems.

Key words: Mucocutaneous leishmaniasis. Sociopsychological aspects. Social discrimination.

\section{REFERÊNCIAS BIBLIOGRÁFICAS}

1. Costa JML. Estudo clínico-epidemiológico de um surto epidêmico de leishmaniose tegumentar americana, na região de Corte de Pedra, Valença, Bahia. Tese de Mestrado, Universidade de Brasilia. Brasilia, 1986.

2. Frist TF. A reabilitação do hanseniano. A Saúde no Brasil 4: 254-260. 1983.

3. Gandra Junior DS. Lepra: Estudo do fenômeno social da estigmatização. Tese de Doutoramento em Antropologia, Universidade Federal de Minas Gerais. Belo Horizonte-MG, 1973.

4. Llanos-Cuentas EA. Estudo clínico evolutivo da leishmaniose em área de Leishmania braziliensis braziliensis Três Braços-Bahia. Tese de Mestrado, Universidade de Brasilia, Brasília, DF, 1984.

5. Ma P, Armstrong D. The acquired immune deficiency syndrome and infections of homosexual men. York Medical Books, New York, 1983.

6. Ministério da Saúde. A Saúde no Brasil 4:197-264, 1983.

7. Netto EM, Tada MS, Golightly I, Kalter DC, Lago EL, Barreto AC, Marsden PD. Conceitos de uma população local a respeito da leishmaniose muco-cutânea em uma área endêmica. Revista da Sociedade Brasileira de Medicina Tropical 18:33-37, 1985.

8. Pitanguy I, Ribeiro A. Leishmaniasis: surgical treatment of its sequeale. Plastic and Reconstructive Surgery 36:565-572, 1965.

9. Rotberg A. Lepra $x$ hanseníase. ARS Curandi 16:60 $69,1983$.

10. Schilder P. A imagem do corpo. Editora Martins Fonseca, São Paulo, p. 1-316, 1980.

11. Tejada A. Leishmaniose tegumentaria en el Perú-investigación epidemiológico-clínica de la leishmaniasis tegumentaria en los departamientos del Cuzco y Madre de Dios. Tesis de Doctorado, Universidad Nacional Mayor de San Marcos. Lima, Peru, 1973.

12. Torres O. A leishmaniose na Bahia. Arquivos Brasileiros de Medicina 7:373-426, 1920. 